\title{
Reformas Neoliberais, Reforma Sanitária Brasileira e Fundações Estatais de Direito Privado: análise de documento da Fundação Estatal de Saúde da Família (FESF) - Bahia
}

Neoliberal Reforms, Brazilian Health Care Reform and Private Law State Foundations:
analysis of a Family Health State Foundation (FESF-Bahia) document

Felipe Monte Cardoso', Gastão Wagner de Souza Campos²

1 Mestrando em Saúde Coletiva da Faculdade de Ciências Médicas pela Universidade Estadual de Campinas (UNICAMP) - Campinas (SP), Brasil. Médico Assistente do Programa de Saúde da Família da Universidade Estadual de Campinas (UNICAMP) - Campinas (SP), Brasil. felipe_mcardoso@yahoo.com.br

2 Doutor em Saúde Coletiva pela Universidade Estadual de Campinas (UNICAMP) - Campinas (SP), Brasil. Professor Titular do Departamento de Medicina Preventiva e Social da Faculdade de Ciências Médicas da Universidade Estadual de Campinas (UNICAMP) - Campinas (SP), Brasil. gastaowagner@mpc.com.br
RESUMO A implantação do Sistema Único de Saúde (SUS) coincidiu com um período da história brasileira hostil a direitos sociais universalistas, no qual se aprofunda o padrão de dominação de classes no País, determinado pela subordinação a interesses externos e por um regime de segregação social. As reformas neoliberais - atual expressão deste padrão - se chocam frontalmente com as proposições da reforma sanitária brasileira. Este estudo analisou um documento da Fundação de Saúde da Família da Bahia, onde se encontraram os principais elementos das reformas neoliberais: a acomodação ao ajuste fiscal, a retirada de direitos dos trabalhadores, a lógica corporativa na gestão dos serviços de saúde.

PALAVRAS CHAVE: Reforma Sanitária Brasileira; Fundações Estatais de Direito Privado; Sistema Único de Saúde; Reformas Neoliberais; Direitos Civis.

ABSTRACT The implantation of the Unified Health System (SUS) has coincided with a period of Brazilian history of hostililty toward universal social rights, in which the pattern of class domination in the country is deepened, determined by subordination to external interests by a regime of social segregation. The process of neoliberal reforms, a current expression of this pattern, clashes head on with the propositions of the Brazilian public health reform. This study has analyzed a document from the Fundação de Saúde da Familia da Bahia, in which the main elements of the neoliberal reforms were found: the accomodation to fiscal adjustment, the removal of worker rights, the corporative logic behind health care service management.

KEYWORDS: Brazilian Health Care Reform; Private Law State Foundations; National Health System; Neoliberal Reforms; Civil Rights. 


\section{Introdução}

Os últimos 20 anos têm sido marcados, no Brasil, por uma série de mudanças na orientação de diversas políticas de estado que podem ser chamadas de 'políticas de ajuste neoliberal' ou 'reformas estruturais neoliberais', cujos núcleos comuns são a adequação da institucionalidade estatal às necessidades do 'capital oligopolista’ como resposta à grave crise dos anos 1980 . Sob o ponto de vista das políticas sociais, os elementos fundamentais das reformas neoliberais são o corte orçamentário e a privatização (SOARES, 1998).

No caso das sociedades latino-americanas, estes processos tornam-se ainda mais graves. A subordinação à dinâmica das grandes corporaçôes transnacionais, o regime de segregação social e a inadequação entre progresso tecnológico e incorporação dos ganhos de produtividade pelo conjunto da população são os traços constitutivos do capitalismo dependente e do subdesenvolvimento, características estruturais destas sociedades (FERNANDES, 2006; FURTADO, 1982; SAMPAIO JÚNIOR, 1999).

Diante dos impasses colocados para o conjunto das políticas sociais, uma série de debates tem sido travada pela sociedade brasileira. Dentro de uma conjuntura de 'restrição crônica ao financiamento dos direitos sociais' existe uma série de propostas de mudança nos 'modelos de gestão' dos serviços públicos, de forma a, supostamente, poder ampliá-los. No caso da saúde, há diversas propostas em execução ou debate: das mais precoces Organizaçóes Sociais (OSs), passando pelas Fundaçóes Estatais de Direito Privado (FEDPs) e pelas recentes Parcerias Público-Privadas (PPPs) e pela Empresa Brasileira de Serviços Hospitalares S.A., todas são propostas de modelos administrativos que alegam dar conta dos impasses na prestação de serviços de saúde no âmbito do Sistema Único de Saúde (SUS).

O objetivo deste trabalho é compreender os fundamentos da Fundação Estatal de Saúde da Família (FESF) - Bahia, que é uma modalidade de FEDP. A importância desta fundação se dá pela relevância do Estado e pela abrangência da mudança de gestão do sistema de saúde em geral, além da força de trabalho, em especial. Este trabalho pretende realizar uma análise do documento 'FESF: SUS Inovação Radical na Estratégia de Saúde da Família' (FUNDAÇÃO ESTATAL SAÚDE DA FAMÍLIA DA BAHIA, 2009), dentro do contexto de ajuste neoliberal vivido pelo Brasil atual.

\section{Capitalismo dependente e democracia restrita}

O longo processo de consolidação do capitalismo brasileiro e da dominação de classe pela burguesia brasileira está ancorado em um traço estrutural fundamental: a existência de uma dupla articulação que atrela o padrão de acumulaçáo e de dominação ao imperialismo e aos anacronismos da sociedade colonial (SAMPAIO JÚNIOR, 1999).

Esta característica resulta de um processo histórico singular, no qual os frutos do desenvolvimento capitalista não são aproveitados em benefício da sociedade nacional:

Os povos de origem colonial ou não participaram desta evolução do capitalismo [dos países centrais], ficando à margem das verdadeiras vantagens desta civilização, ou participaram dela como colônias, semicolônias e naçôes dependentes. (FERNANDES, 2000, p. 108).

Este processo teve o significado histórico de uma revolução burguesa 'atrasada' ou 'interrompida'. Isto significa que existe uma dissociação:

O circuito da revolução é interrompido no patamar a partir do qual os seus dividendos seriam compartilhados seja com os 'menos iguais' das classes dominantes, seja com os 'de baixo'. A interrupção só fica evidente por meio de um artificio comparativo: o que se sucedeu em outros casos análogos dos paises centrais e o que aconteceria se [...] De fato, o raio dessas revoluçôes é tão pequeno que seria uma 'anomalia' se elas ocorressem de outra forma. (FERNANDES, 1981, p. 75).. 
Isto quer dizer que as 'mudanças sociais construtivas' das revoluçóes burguesas clássicas - dentre elas, a generalização de liberdades individuais e coletivas -, além do amplo acesso aos bens e serviços produzidos em uma determinada coletividade não fazem parte $\mathrm{da}$ consolidação do poder burguês no Brasil. O padrão de dominação de classes engendrado e consolidado pelo regime ditatorial é chamado, por esse autor, de 'autocrático-burguês'; a expressão histórica do coroamento da revolução burguesa, 'atrasada' ou 'interrompida',

[...] serviu de fulcro à reaglutinação e à reorientação da dominação burguesa, adaptando-se às complexas e drásticas exigências de uma rápida transição para o capitalismo monopolista, sob impulsáo e controles externos. (FERNANDES, 1995, p. 135).

O padrão de luta de classes próprio deste regime é decorrente de uma profunda assimetria na correlação de forças, em que o poder político é monopolizado por uma classe dominante impotente para fazer frente à dominação externa, e totipotentes para impor unilateralmente sua vontade ao conjunto da população (SAMPAIO JÚNIOR, 1999). Assim, a dinâmica de transformaçáo política e socioeconômica nestas sociedades é extremamente penosa:

[...] privados de meios de organização e consciência, de participação social, econômica e politica, os de baixo gravitam em um mundo de minimos politicos. Demoram décadas para alcançar o que poderia ser feito em meses e perdem em uma cartada (aplicada sem dó pelos de cima) o fruto de longos anos de laboriosa porfia com o destino. (FERNANDES, 1985, p. 135).

Para Lopez e Mota (2008), esta situação não se altera substancialmente até os dias de hoje:

[...] nesta história, o que sobra mesmo, é o modelo autocrático-burguês, persistente, presente nos dias que fluem como naqueles em que
Florestan Fernandes o detectou, em 1975, em sua obra clássica. Tal modelo náo foi desmontado, embora as aparências de uma democracia liberal levem a pensar estar-se vivendo em um modelo de República democrático-burguesa. [...] No Brasil, a autocracia mudou de forma, modernizou-se, mas as remanescências de uma ordem e do mores burocrático-estamental inseriram-se em uma sociedade de classes - que absolutamente ignora o que significa contrato social, mal formada e mal educada, impregnando-a e amoldando-a a sua imagem e semelhança. (p. 979-980).

Em um contexto em que a democracia brasileira ganha os contornos de uma 'democracia restrita' aos círculos dominantes, cabem consideraçóes sobre como as reivindicaçôes em torno da 'democratização progressiva', tấo caras ao movimento de luta pela reforma sanitária, se chocaram com a ordem social e política brasileira.

\section{Reforma Sanitária Brasileira, SUS e Reformas Neoliberais}

Dentro do conjunto da efervescência social de fins das décadas de 1970 e de 1980, o movimento pela Reforma Sanitária Brasileira (RSB) tem importância fundamental não apenas pela criação do SUS - uma de suas bandeiras mais importantes -, mas pela defesa de um direito à saúde em sentido amplo. De forma sintética, a RSB pode ser vista

[...] como uma reforma social centrada nos seguintes elementos constituintes: a) democratização da saúde, o que implica a elevação da consciência sanitária sobre saúde e seus determinantes e o reconhecimento do direito à saúde, inerente à cidadania, garantindo o acesso universal e igualitário ao Sistema Único de Saúde e participação social no estabelecimento de politicas e na gestão; b) democratização do Estado e seus aparelhos, respeitando o pacto federativo, assegurando a descentralizaçâo do 
processo decisório e o controle social, bem como fomentando a ética e a transparência nos governos; c) democratização da sociedade alcançando os espaços da organização econômica e da cultura, seja na produção e distribuição justa da riqueza e do saber, seja na adoção de uma 'totalidade de mudanças', em torno de um conjunto de politicas públicas e práticas de saúde, mediante uma reforma intelectual e moral. (PAIM, 2008, p. 173).

Dentro deste espírito de 'totalidade de mudanças', no relatório da VIII Conferência Nacional de Saúde, profundamente influenciado pelas proposiçóes do movimento sanitário e de defesa do direito à saúde, o relatório da VIII Conferência Nacional de Saúde destaca a importância da determinação social do processo saúde e doença, expressa, entre outras formas, pela defesa da suspensão imediata dos juros da dívida externa, bem como o não pagamento desta; da reforma agrária subordinada às necessidades dos trabalhadores do campo e sob o controle destes; de direitos amplos à educação, ao trabalho, à organização e à greve (CONFERÊNCIA NACIONAL DE SAÚDE, 1986).

Atualmente, chama a atenção o hiato entre as proposiçốes democráticas radicais do movimento original e o caráter restrito da democracia brasileira. No campo do direito à saúde, a pergunta sobre 'o que deu errado na reforma sanitária?' tem sido debatida em diversas publicaçóes (FLEURY, 1997; FALEIROS et al., 2006; CAMPOS, 2007; CENTRO BRASILEIRO DE ESTUDOS DE SAÚDE, 2008; PAIM, 2008). No entanto, na atual conjuntura, o acesso aos serviços de saúde continua, de diversas formas, bloqueado, e o processo de adoecimento da população está em descompasso com o devido ao posto de sexta economia mundial ocupado pelo Brasil: na América Latina, a expectativa de vida brasileira (2011) só é maior do que a de El Salvador, a da Nicarágua, a da Guiana, a da Bolívia, a do Haiti, a da Jamaica, a de Trinidad e Tobago e a do Suriname; nossa mortalidade infantil (2009) é o dobro da mexicana e da argentina, mais do que o triplo da chilena e quatro vezes maior do que a cubana, além de também ser maior do que a da Colômbia, a da Guiana, a do Panamá e a do Suriname (OPAS, 2012). Segundo a PNAD 2009, três em cada dez domicílios brasileiros vivem em situação de insegurança alimentar, mesmo sendo o combate à fome um dos pilares da política social do último governo. $\mathrm{O}$ uso indiscriminado de agrotóxicos no Brasil, que representa $20 \%$ do mercado mundial para o setor, já contamina pelo menos $37 \%$ da amostra testada pela ANVISA, e está relacionado à epidemia de suicídios nas áreas do agronegócio (CARNEIRO et al, 2012).

Neste sentido, o alcance incompleto e descontínuo das conquistas do movimento de reforma sanitária se relaciona à inviabilidade da estratégia de conquistas progressivas e cumulativas de direitos universais no interior do Estado brasileiro. O amplo domínio do grande capital sobre todas as esferas da sociedade e do poder estatal, bem como o ataque permanente aos direitos da classe trabalhadora (previdência, leis trabalhistas, organização sindical, educação pública, entre outros) escancaram os estreitos limites do capitalismo dependente. O que agrava o cenário é o enfraquecimento objetivo e subjetivo do conjunto das forças sociais e políticas tributárias da luta dos anos 1970-1980¹.

Cabe, ainda, um balanço sobre o maior produto do movimento pela RSB, o Sistema Único de Saúde. Como objetivo deste texto, não se pretende uma consideração longa a este respeito, mas é preciso listar alguns elementos que condicionam os avanços e retrocessos da política pública de saúde no Brasil2:

1) A coexistência de um setor privado de segurossaúde, que se fortaleceu e é tendencialmente hegemônico - Permitida pela Constituição Federal de 1988, é um dos principais bloqueios estruturais ao aprofundamento do caráter público do SUS:

Parece grave notar que o paralelismo do subsistema privado em relação ao SUS produz

\footnotetext{
Para um discussão sobre aspectos atuais desta crise, conferir SAMPAIO JUNIOR, P. A. Brasil: as esperanças não vingaram. Buenos Aires: CLACSO, 2005.

${ }^{2}$ Não se quer, aqui, dizer que os pontos a seguir resumem integralmente os problemas que bloqueiam a implantação do SUS. O que se quer ressaltar é como os três pontos elencados colocam óbices estruturais para que questões como essas não consigam superar a marginalidade na construção do SUS, ou, em outras palavras, tornarem-se hegemônicas.
} 
efeitos nocivos sobre a regulação do sistema de saúde (ausência de planejamento), sobre o financiamento público (elevação dos custos, renúncia fiscal, boicote ao ressarcimento), sobre a organização dos profissionais de saúde (dupla militância), sobre a regulação da incorporação tecnológica (pressão do complexo médico-industrial) e sobre a equidade do acesso (dupla porta de entrada, dada a capacidade de pagamento da clientela da medicina privada). (OCKÉ-REIS; SOPHIA, 2009, p. 73) ${ }^{3}$.

Isto significa, na prática, a existência de dois sistemas de saúde no Brasil: um para os ricos e remediados, e outro para os 'deserdados'. No limite, comprime o SUS para as margens de uma política pública focalista, isto é, para o seu inverso.

2) A sucessão de ataques ao financiamento dos direitos sociais nas décadas de 1990 e 2000 - Desde os vetos de Collor aos pontos sobre financiamento ao SUS, nas leis no 8.080 e no 8.132 ; passando pela criação do que hoje se chama Desvinculação das Receitas da União (DRU), pela criação do regime de metas de inflação, pela perenização da Lei de Responsabilidade Fiscal (LRF), pelas propostas de reforma tributária que são, simplesmente, desoneração do capital, entre outros pontos, o financiamento dos direitos sociais - incluindo a saúde - sofre a violência da política de ajuste fiscal, isto é, do sacrifício dos direitos democráticos em detrimento da remuneração da burguesia rentista, nacional ou internacional, que vive da dívida pública brasileira. Isto faz Santos (2009) afirmar que

\section{[...] o financiamento do SUS é ineficiente, a} ponto náo somente de impedir a implementaçâo progressiva e incremental do sistema, como e principalmente de avançar na reestruturação do modelo e procedimentos de gestão, em função de cumprimento dos princípios constitucionais. (p. 14).
3) As novas formas de gestão da força de trabalho Em decorrência do processo acima, em especial da LRF, que coloca limites estreitos para o gasto com pessoal, os governos que se sucederam no período, todos agentes do ajuste fiscal, propuseram reformas administrativas que enquadrassem as políticas públicas dentro dos limites do consenso neoliberal. Exemplos são as Organizaçôes Sociais (OSs), as Parcerias Público-Privadas (PPPs) e as Fundações Estatais de Direito Privado (FEDPs).

No conjunto, os pontos acima sintetizam o que significa o 'processo de reformas neoliberais' ou de 'ajuste neoliberal' no setor saúde. O termo é controverso e objeto de muitas polêmicas na sociedade brasileira, apresentando diferentes significados para diversos autores e atores sociais. Para uma compreensão adequada deste processo histórico, é preciso, em primeiro lugar, chamar a atenção para "[...] a distância existente entre os processos 'reais' e as 'doutrinas' assumidas pelas políticas de estabilização" (SOARES, 1998, p. 37). O discurso clássico dos defensores de reformas neoliberais estrutura-se a partir da alegada necessidade de 'redução do Estado' em detrimento da 'desregulamentação da economia', de forma a dar vazão aos desígnios do 'mercado' e fazer avançar o 'desenvolvimento capitalista’. Essa visão, porém, abstrai “[...] o papel histórico desempenhado pelo Estado na estruturação do nosso capitalismo" (SOARES, 1998, p. 271).

Além disso, mesmo com o padrão atual de acumulação capitalista, que deslocou "[...] as grandes decisôes sobre financiamento, transferência de tecnologia, produção e comércio da órbita institucional predominantemente pública para a predominantemente privada”, isto não significou a 'retirada do Estado'. Ao contrário,

mesmo com o aprofundamento da crise econômica [...], quando a tendência dominante se desloca para o controle das políticas monetária e fiscal de ajuste macroeconômico, o Estado não só não abre mão do seu papel estruturante, como em alguns casos assume medidas claramente

\footnotetext{
${ }^{3}$ Outro ponto importante a respeito das assimetrias de classe internamente ao SUS, que representa a'outra ponta' das desigualdades sociais no atendimento à saúde, é o fato de que procedimentos mais deficitários, como atendimento ao politraumatizado, complicações prolongadas de transplantes e terapia intensiva, são cobertos exclusiva ou majoritariamente pelo próprio SUS
} 
neoprotecionistas diante do agravamento das condiçóes de concorrência. (SOARES, 1998, pp. 271-272).

Em outras palavras, o processo de reformas neoliberais não se expressa na dicotomia 'mais Estado $\mathrm{x}$ menos Estado'4, mas em uma mudança qualitativa a respeito do papel do Estado nos marcos da fase atual do capitalismo.

Para efeitos deste texto, o 'processo de reformas neoliberais' significa o conjunto de modificações institucionais no âmbito do Estado Nacional que procuram: 1) Retirar a capacidade do Estado Nacional de controlar as variáveis mais importantes relativas à soberania nacional frente aos desígnios do grande rentismo; 2) Restringir o gasto público, em geral, mas especialmente no que diz respeito aos direitos sociais. Como exemplos se podem citar a restrição aos gastos com moradia, a reforma agrária, e, como exposto acima, a saúde; 3) Vender o patrimônio nacional, isto é, privatizar - aberta ou veladamente - as empresas públicas nacionais, bem como o patrimônio natural do País, como os minérios e a terra, com vistas à expansão do agronegócio; 4) Privatizar os direitos sociais, isto é, mercantilizar 'serviços' que deveriam ser direitos garantidos pelo Estado: saúde, educação, previdência, moradia e transporte, em escalas e naturezas diferentes.

Diga-se que a tendência de saturação mercantil de todas as esferas da vida social é um componente estrutural das transformaçóes recentes da sociedade capitalista discutidas por Mészaros (2007). Esta tendência, ao ser analisada sob o ponto de vista da reforma dos estados nacionais na América Latina, é expressa por Boron (2004) nos seguintes termos:

Cuando estos 'retoques' duran más de diez años pierden el dicho carácter y se convierten em proyectos - muchas veces caóticos e incoherentes, y siempre furtivamente coercitivos - de fundar un novo tipo de sociedad. Esto último es precisamente lo que ha ocurrido em América Latina: capitalismo neoconservador, sociedades duales, marginación de las masas otrora integradas, ruptura del tejido social y desagregación de los mecanismos de integración, capitulación de la soberania nacional, degradación de la politica, etc. (p. 260).

Desde o começo dos anos 1990, sobram exemplos de medidas que se enquadram nesta discussão: nos governos Collor (privatizaçóes e abertura financeira), FHC (venda da Vale do Rio Doce e da Telebras, e reformas da previdência e administrativa), Lula (nova reforma da previdência e privatizaçáo de rodovias) e Dilma (privatização da Infraero) há uma linha de continuidade de reformas neoliberais. Independentemente das diferenças dos projetos de cada agrupamento político e de seus governos, o fato essencial é que os problemas fundamentais da sociedade - , como reforma agrária, moradia, garantia de emprego com condiçôes de trabalho e salários dignos - esbarram no modelo que privilegia a remuneração dos oligopólios transnacionais.

No caso do gasto público, embora tenha havido diferenças entre as décadas de 1990 e 2000, como a expansão de programas de transferência de renda, o subfinanciamento global dos direitos sociais persiste. $\mathrm{O}$ gasto federal com saúde, educação, trabalho e emprego, e Desenvolvimento Social e Combate à Fome somou apenas R\$ 242 bilhões (5,85\% do PIB) em 2011 (CHAVES; RIBEIRO, 2012), enquanto o gasto federal com juros e amortização da dívida pública correspondeu a $\mathrm{R} \$ 708$ bilhôes (17,9\% do PIB) (FATORELLI; ÁVILA, 2012). Em 2009, no caso da saúde, os gastos totais (públicos e privados) foram de $\mathrm{R} \$ 276,6$ bilhóes (8,8\% do PIB), dos quais mais da metade ( $4,8 \%$ do PIB) foi privada. Dos gastos públicos, metade foi executada pela União (IBGE, 2012). Sinteticamente, o padrão observado é:

\section{Limitam-se os gastos sociais às politicas de cunho focalizado como transferência de renda,}

\footnotetext{
${ }^{4}$ Um exemplo é a evolução da carga tributária brasileira em relação ao PIB: em 1965, representou 19\% deste; em 1986, 26,2\%; em 1990, 25,21\%; em 1996, 28,97\%; e em 2007, $35,3 \%$. O peso do Estado no Brasil aumentou, ainda, a partir do início do processo de reformas neoliberais (ORGANISATION FOR ECONOMIC CO-OPERATION AND DEVELOPMENT, 2008).

${ }^{5}$ Por exemplo, medidas macroeconômicas que limitem o controle da moeda, do câmbio, das barreiras alfandegárias, com o sentido de assegurar a livre movimentação do capital em todas as suas morfologias, seja ele 'especulativo' ou 'produtivo'
} 
como o Bolsa Familia, em desfavor de politicas sociais mais universais, de avanço de serviços sociais mais amplos, como os do âmbito da saúde pública e universal. Em paralelo a isso, atende-se a interesses do setor financeiro e do grande capital industrial do Brasil, que vêm sendo os grandes beneficiários desta politica. (FATORELLI, 2013).

\section{Fundação Estatal de Direito Privado no contexto da contrarreforma do Estado}

No caso dos modelos de gestão, diversas modalidades têm sido propostas em decorrência da reforma administrativa de Bresser-Pereira (1995-1998), que tinha os pressupostos de garantir flexibilidade e agilidade para a máquina pública. Um dos modelos, as Organizaçóes Sociais (OSs) são assim definidas por Ibañez e Vecina Neto (2007):

[tem] personalidade jurídica de direito privado, não estando submetida às normas do direito público: as obrigaçóes estabelecidas pelo contrato de gestão; associação sem finalidade lucrativa ou fundação de direito privado qualificada pelo poder público para exercer atividade pública descentralizada; com o objetivo específico de oferecer mais autonomia e flexibilidade ao serviço público com aumento de eficiência e qualidade; regime CLT sem concurso público; tem privilégios tributários". Este modelo foi alvo de diversas criticas. (ASSEMBLEIA LEGISLATIVA DE SÃO PAULO, 2008; PAHIM, 2009).

Para Paim e Teixeira (2007), a FEDP viria no sentido da

[...] necessidade de experimentar novos formatos institucionais permeáveis à gestão compartilhada pela sociedade civil, trabalhadores da saude e governo, com garantia de um corpo técnico estável através de seleção pública e carreiras especificas".

Estes autores, no entanto, ressalvam que o modelo per se não traz soluçôes: é necessário acabar com a restrição orçamentária à saúde e avançar com a democratização do Estado:

A 'Reforma do Estado' empreendida na década de 90 para torná-lo 'gerencial', regulador, fora da produção econômica e da prestação de serviços é distinta de uma Reforma Democrática do Estado para torná-lo efetivamente público. Esta passa pela radicalização da democracia e da Reforma Sanitária Brasileira, implantação da Seguridade Social e desenvolvimento do SUS, e pela formulação e condução de politicas contrahegemônicas. (p. 1828).

Para Sara Granemann (2008), porém, a proposta da FEDP é a continuidade do processo de 'contrarreformas de Estado' iniciado por FHC, pois o objetivo declarado da proposta de FEDP era o de regulamentar a Emenda Constitucional 19/98 (MPOG, 2007 apud GRANEMANN, 2008). Segundo esta autora, três aspectos do projeto embasam sua posição: ele representa a 'privatização das políticas sociais', o 'ataque aos trabalhadores' e o impacto ideológico causado pelo 'fetiche da grande empresa'.

Com relação ao primeiro aspecto, o caráter privatista fica explícito na citação do documento: "[...] setores em que cumpre ao Estado atuar de forma concorrente com a livre iniciativa, exercendo atividades que, embora consideradas de relevância para o interesse público, não lhe sejam exclusivas". (MPOG; 2007 apud GRANEMANN, 2008, p. 37). Em suma, os direitos sociais que 'não são exclusivos' ao setor público - como saúde, educação ou cultura - seriam garantidos em lógica privada, necessariamente, pela 'concorrência com a livre iniciativa', e não pela superação da lógica mercantil.

O segundo aspecto é corolário do primeiro e tem quatro componentes. O primeiro diz respeito 
à precarização do vínculo trabalhista, rebaixado de estatutário para celetista. A argumentação está no escopo da lógica privada.

Por outro lado, nas áreas em que atua de forma concorrente com a iniciativa privada, é indispensável que o Estado possa aplicar o regime de emprego celetista, mais flexivel e aberto à inovação e à especialidade, atributos essenciais a quem atua em ambiente concorrencial e precisa garantir a qualidade dos serviços e a incorporação de novas tecnologias geradas para o setor. (MPOG, 2007 apud GRANEMANN, 2008, p. 38).

O segundo componente diz respeito à modalidade de contratos de gestão ${ }^{6}$. Estes, sob a bandeira da eficiência da coisa pública, na verdade, têm constituído engenhoso expediente para 'poupar' recursos estatais em detrimento de ganhos salariais, da degradação das aposentadorias, da piora das condições do serviço público, do aumento da exploração dos servidores, como se encontrou em São Paulo.

$\mathrm{O}$ terceiro componente se refere à fragmentação imposta pelo projeto à categoria dos servidores públicos ${ }^{7}$, que tem reduzido ainda mais seu poder de reivindicação frente à compressão salarial e à piora das condições de trabalho.

O último componente consiste no 'direito' que as FEDPs adquirem, de não contribuirem com o fundo público estatal, o que representa mais um dos numerosos ataques ao financiamento da Seguridade Social, agravando o cenário de subfinanciamento deste setor:
$O$ recolhimento de impostos e de contribuiçóes para a seguridade social (previdência, assistência e saúde) objetiva a formação do fundo público, de orçamento que financiará as politicas sociais, elas mesmas instrumentos que viabilizam os direitos e a proteção social da força de trabalho ocupada e excedente. Ora, as fundaçôes estatais venderão seus serviços ao Estado e a outros agentes do mercado. De uma parte reivindicarão do Estado recursos para realizar a prestação de serviços e de outra náo contribuirão para a formação do fundo público que sustenta a própria 'politica social' executada pela fundação porque esta, ao prestar serviços sociais, gozará de imunidade tributária. (GRANEMANN, 2008, p. 38-39).

Por fim, ressalte-se que, no projeto das FEDP, o controle social seria feito sob os marcos do 'controle corporativo', isto é, no modelo da grande empresa, e não nos princípios norteadores do SUS. Assim,

\section{[...] no que afeta ao Projeto Fundação Estatal, somente no Conselho Consultivo Social mencio- na-se a presença de 'representantes da sociedade civil, aí incluidos os usuários e outras pessoas físicas ou jurídicas com interesse nos serviços da entidade. Dado que 'sociedade civil' é o mais abrangente dos termos cunhados pelo liberalis- $m o^{8}$ em uso em nosso país pelos últimos gover- nos, cumpre observar que neste conceito cabem desde as representaçóes do capital, da força de trabalho, das ONGs e de tantas outras formas representativas de interesses privados, tem-se,}

\footnotetext{
${ }^{6}$ Ibañez e Vecina (2007) assim definem o contrato de gestão: "'Contrato de gestão' objetivos, metas, prazos, critérios de controle e avaliação, obrigações e responsabilidades de seus dirigentes; investimento anual com base em percentual de receitas em ações de inovação, capacitação de pessoal, adequação mobiliária e imobiliária; fixação de teto percentual para gastos com pessoal; dirigentes com penalidade de perda de mandatos no caso de descumprimento do contrato de gestão injustificadamente".

7 Um exemplo desta fragmentação é o caso do Estado de Sergipe, onde foram criadas três FEDPs: uma para atenção básica e educação permanente (FUNESA), outra para assistência hospitalar e urgência e emergência (FHS), e a última para serviços laboratoriais, verificação de óbito e prestação de serviços vinculados à hemoderivados (FSPH). Editais disponíveis no site da Secretaria de Estado de Saúde. SECRETARIA DE ESTADO DE SAÚDE. Disponível em: <http://www.ses.se.gov.br>. Acesso em: 25 mar. 2010.

${ }^{8} \mathrm{O}$ conceito de 'sociedade civil' é objeto de grande polêmica no campo da ciência política. Em crítica semelhante à da autora, a obra citada de Bianchi (2008) apresenta extenso debate a este respeito, à luz da teoria de Antonio Gramsci, que, ao realizar uma crítica ao que chama de 'leitura hegemônica' da obra deste autor, afirma que: "Mantendo sociedade civil e sociedade política uma relação de unidade-distinção, formam dois planos superpostos que só podem ser separados com fins meramente analíticos. [...] A incompreensão dessa unidade orgânica entre sociedade civil e sociedade política tem levado alguns autores a afirmarem que Gramsci teria caracterizado a sociedade civil como uma esfera autônoma do Estado.

Destaca, ainda, que este conceito tem dois aspectos: "No primeiro, a sociedade civil está associada às formas de exercício e afirmação de uma classe sobre o conjunto da sociedade. (...) No segundo, frequentemente apresentado entre aspas, destaca a capacidade de iniciativa econômica que o Estado possui no capitalismo contemporâneo" (p. 182-185).
} 
então, um severo rebaixamento do que se defende no SUS como controle social. Ademais, a Proposta Fundação Estatal para o Conselho Consultivo Social subordina-o ao Conselho Curador - também denominado Administrativo - e não se pronuncia sobre sua composiçāo numérica. (GRANEMANN, 2008, p. 39).

A análise acima procura demonstrar que o projeto das FEDPs está articulado com o processo de reformas neoliberais, que agravam as características 'selvagens' de nosso capitalismo - no caso do projeto, pelo tratamento à questáo da força de trabalho e na defesa da concorrência como motor do aperfeiçoamento dos direitos sociais, bem como na restrição à constituição do fundo público. Pode-se acrescentar ainda que, ao acomodar-se aos limites da Lei de Responsabilidade Fiscal, este processo é orgânico à política de ajuste fiscal vigente.

\section{A Proposta da Bahia}

Diante dos impasses encontrados pelo governo federal para colocar em votação o projeto das FEDPs, alguns entes federativos se anteciparam na proposição da implementação do modelo. Vai-se estudar aqui o caso da Fundaçáo Estatal de Saúde da Família da Bahia, tendo como base o documento 'Inovação Radical na Estratégia Saúde da Família na Bahia', de 2009.

A justificativa da mudança de modelo tem diversas componentes, entre as quais, indicadores de saúde 9 . O documento, que atribui a maior parte desses problemas a falhas estruturais da atenção básica, toca, adiante, em um ponto extremamente sensível do SUS: as dificuldades, em grande medida relacionadas à força de trabalho, para organizar a atenção básica no conjunto de um estado: dificuldades de contratação, instabilidades das equipes, problemas para uma política salarial uniforme e que contemple as necessidades do conjunto dos municípios da Bahia ${ }^{10}$. Além disso, a inadequação da formação universitária, dificuldades para uma política de educação permanente, vieses 'produtivistas' de setores da gestão, bloqueios à democracia participativa e desequilíbrios regionais (com prejuízo dos pequenos municípios no que diz respeito principalmente a capacidades técnica e política de construir uma política de $\mathrm{AB}$, além das distorçôes políticas) fecham o cenário das principais dificuldades para o fortalecimento da atenção básica naquele Estado, conforme a avaliação do documento.

\section{A novidade do modelo}

Para superar estes problemas, a FESF aparece como uma mudança de paradigma que trará segurança e estabilidade para todos os segmentos. Entre as justificativas, estariam melhores condiçóes de trabalho e melhora da qualidade da atenção:

Trabalhadores, que passam a contar com um emprego público, com acesso através de concurso, direitos trabalhistas e previdenciários garantidos, com uma carreira que valoriza e estimula a formação e desenvolvimento profissionais, e a segurança de que vai receber remuneração justa, em dia, e que progredirá ao longo da sua carreira; Usuários, que contarão com um serviço em funcionamento permanente, acessivel, próximo à sua casa, acolhedor, humanizado e de qualidade, que buscará ouvir sua opinião e estimular a sua participação, promovendo $e$ cuidando da saúde deste usuário e de sua família, não a desamparando nos momentos de sofrimento e doenças agudas. (FUNDAÇÃO ESTATAL SAÚDE DA FAMÍLIA DA BAHIA, 2009, p. 19-20).

9"[...] a maior taxa de incidência de tuberculose, a mais elevada razão de mortalidade materna e a maior proporção de crianças com baixo peso ao nascer da Região Nordeste" (FUNDAÇÃO ESTATAL SAÚDE DA FAMílIA DA BAHIA, 2009, p. 8).

10 "Menos de 21\% dos municípios da Bahia possuem enfermeiro com vínculo estatutário: menos de 12\%, algum médico; e menos de $8 \%$, algum cirurgião-dentista. Na imensa maioria dos casos, as relações de trabalho são precárias (sem a garantia dos direitos e com vínculos terceirizados) e o trabalhador fica sem proteção em situaçōes de afastamento e doenças, e muito vulnerável a todo o tipo de arbitrariedade, dada a elevada instabilidade no emprego" (FUNDAÇÃO ESTATAL SAÚDE DA FAMÍLIA DA BAHIA, 2009, p. 13). 
No entanto, a defesa do modelo de fundação estatal é feita resgatando-se os argumentos do governo federal a partir de 2005 e o processo político induzido pelo governo estadual a partir de 2007, que contou com ampla adesão dos municípios. Define a FESF como

[...] um organismo da administração indireta, parte do Estado, sem fins lucrativos, de interesse coletivo, dotado de personalidade jurídica de direito privado. Trata-se de uma forma de descentralização e especialização do Estado Brasileiro para prestar serviços sociais com maior efetividade, agilidade e qualidade aos cidadãos. (FUNDAÇÃO ESTATAL SAÚDE DA FAMÍLIA DA BAHIA, 2009, p. 27).

Avançando na apresentação, faz-se uma diferenciação entre outros entes da administração pública e o porquê de um novo modelo, seguido por um quadro comparativo. A FESF seria diferente porque

\section{As Fundaçôes Estatais (FE) nascem da consta-} tação de que o Estado precisava de uma outra figura da administração pública, diferente da administraçâao direta, das autarquias e das empresas estatais, para ter mais qualidade, universalidade e agilidade na prestação de serviços públicos que são direito do cidadão e dever do Estado. (FUNDAÇÃO ESTATAL SAÚDE DA FAMÍLIA DA BAHIA, 2009, p. 29).

Desta forma, ainda que a FESF se proponha a combater desvios gritantes que ocorreram no processo de implementação do SUS, como no caso de alguns aspectos da descentralização, seu modelo está conforme aos limites impostos pelo processo de reformas neoliberais. Mais ainda, o bloco de poder que a propóe parte do princípio de que a coisa pública é legitimada ao assumir a morfologia e o funcionamento da coisa privada, ainda que

\section{[...] a FESF-SUS só pode prestar serviços ao} setor público, isto é, está vedada a cobrança direta ou indireta dos seus serviços aos usuários ou a venda de serviços a empresas privadas e planos de saúde. Ela não produz bens e serviços para o mercado, só para o setor público e mediante contrato de gestão. Seus serviços são universais, sendo vedada a 'dupla porta' de acesso e a segmentaçấo da clientela. (FUNDAÇÃO ESTATAL SAÚDE DA FAMÍLIA DA BAHIA, 2009, p. 34).

A consideração que cabe: Por que a correção dos desvios não é feita no âmbito da administração pública direta? Ou, ainda, por que, no caso da necessidade de se criar autarquias ou fundaçóes, náo se apela para o direito público?

\section{O regime de trabalho, os vencimentos e as carreiras}

Na justificativa do projeto, demonstra-se que

Menos de $21 \%$ dos municípios da Bahia pos-
suem enfermeiro com vínculo estatutário; me-
nos de $12 \%$, algum médic;o e menos de $8 \%$,
algum cirurgiáo-dentista. Na imensa maioria
dos caso,s as relaçôes de trabalho são precárias
(sem a garantia dos direitos e com vínculos
terceirizados) e o trabalhador fica sem prote-
ção em situaçóes de afastamento e doenças e
muito vulnerável a todo o tipo de arbitrarie-
dades, dada a elevada instabilidade no empre-
go. (FUNDAÇÃO ESTATAL SAÚDE DA
FAMÍLIA DA BAHIA, 2009, p. 13).

A solução para a 'precarização' é o concurso público com contrato pela Consolidação das Leis do Trabalho (CLT).

A precarizaçáo é um conceito relativo. Um trabalhador hipotético, sem vínculo formal, quando passa a ter outro emprego regido pela CLT, está menos precarizado. O contrário também é verdadeiro: um trabalhador do serviço público, estatutário, quando passa a ser contratado pela CLT por outro ente que não a administração pública, está mais precarizado. Sob o ponto de vista do trabalho, o 
vínculo estatutário é, no geral, melhor, pois oferece mais estabilidade e segurança para o servidor poder dedicarse à carreira, bem como, em alguns casos, certos direitos (licença-prêmio, entre outros). A aposentadoria integral foi, infelizmente, um direito atacado pela contrarreforma previdenciária de 2003. A bandeira do capital tem sido o nivelamento por baixo, em escala nacional, do regime da força de trabalho do setor público (no caso, pelo regime celetista). É evidente, entretanto, que este não é o seu limite. Isto abriria, inclusive, uma prerrogativa para os demais serviços públicos serem nacionalmente nivelados pelo padrão novo, avançando para um mercado de trabalho nacional com piores condiçóes para os trabalhadores.

Mais especificamente, uma análise mais detalhada das propostas de vencimentos do primeiro concurso (presentes no documento em análise) demonstra que: apesar de serem carreiras igualmente indispensáveis ao Programa de Saúde da Família, a relação de salário-base entre um médico de saúde da família e um enfermeiro (não havendo indicações sobre os locais de trabalho, embora, suponha-se que a maior parte deles vá para a atenção básica) é de 2:1, podendo chegar a 2,5:1, contando-se os vencimentos máximos possíveis. Essa diferença se ancora, evidentemente, na escassez absoluta e relativa destes profissionais, principalmente, ao se considerar a realidade nordestina. No entanto, ficam as perguntas: É o mercado o principal delimitador da política pública em saúde? Qual é o potencial desagregador desta medida para o trabalho em equipe? $\mathrm{E}$ chama a atenção, ainda, o desnível entre a carreira de médico de família e de sanitaristas. Este fato está intimamente relacionado à precarizaçáo da gestáo operada em diversas esferas de governo.

Para não realizar uma análise extensa, cabe aqui apenas mais uma questão: Por que o Adicional de Localização (AL) - definido para lugares com dificuldades de fixar servidores, entre outros) - máximo é de $50 \%$ para enfermeiros e $100 \%$ para médicos? O critério é meramente mercadológico, ainda?

\section{A restrição ao processo democrático}

A cartilha reitera o compromisso da FESF com a gestão participativa ao dizer que

\section{[...] como qualquer instituição pública do SUS, está subordinada ao Controle Social, e radicaliza e aprofunda esse princípio ao ter como órgãos deliberativos de direção, conse- lhos que se constituem como esferas públicas de participação social e gestão compartilhada. (FUNDAÇÃO ESTATAL SAÚDE DA FAMÍLIA DA BAHIA, 2009, pp. 34-35).}

$\mathrm{Na}$ análise da estrutura de poder da FESF, observa-se a existência de quatro esferas assim descritas:

O Conselho Curador, órgão deliberativo de direção superior, controle e fiscalização; $O$ Conselho Interfederativo, órgão consultivo $e$ de supervisão superior; A Diretoria Executiva, órgão de direçáo subordinada e de administração superior; O Conselho Fiscal, órgáo de controle interno da FESF-SUS. (FUNDAÇÃO ESTATAL SAÚDE DA FAMÍLIA DA BAHIA, 2009, p. 39).

No entanto, há um enorme desequilíbrio na representação do órgão máximo (Conselho Curador) da FESF: de um total de 14 membros, a gestão conta, ao todo, com 9 representantes: 4 secretários municipais das regióes, 1 secretário municipal indicado pelo Conselho de Secretarias Municipais de Saúde (COSEMS), 2 representantes da SESAB, 2 representantes do governo da Bahia; os trabalhadores da saúde têm, ao todo, 3 representantes: 2 dos trabalhadores da fundação (eleição direta) e 1 do Conselho Estadual de Saúde indicado pelo mesmo dentre a representação dos trabalhadores; os segmentos de usuários (1 representante do Conselho Estadual de Saúde indicado pelo mesmo dentre os usuários); e as universidades públicas da Bahia têm direito, cada um, a 1 representante.

Os números da composição do Conselho Curador revelam o caráter da democracia pretendida pela gestão. Se é fato que sua composição não inclui ONGs ou congêneres, é fato, ainda, que o peso político efetivo dos segmentos preconizados pelos princípios do SUS. Em um espaço em que a força decisória cabe principalmente aos gestores, o papel que cabe ao conjunto da 
força de trabalho (da saúde e/ou usuários do SUS) será por demais reduzido. Isto representa um retrocesso que se torna ainda mais grave ao se considerar o patamar estabelecido pela Constituição Federal de 1988: 50\% de usuários, $25 \%$ de trabalhadores de saúde e $25 \%$ de gestores e prestadores de serviço.

\section{Considerações Finais}

As propostas de 'novos modelos de gestão', cujos principais representantes são Organizaçôes Sociais/Organizaçôes da Sociedade Civil de Interesse Público (OSs/ OSCIPs) e Fundações Estatais de Direito Privado (FEDPs), surgem em um contexto histórico no qual o processo de reformas neoliberais se agrava. Suas raízes mais profundas estão ligadas à consolidação do padrão de dominação de classes, que não foi superado pela redemocratização.

No caso específico da saúde, estas reformas (ou contrarreformas) têm como uma de suas principais expressões o congelamento da implantação do SUS. Em outras palavras,

\section{[...] os Governos que sucederam ao impeach-} ment na conjuntura pós-constituinte (Itamar Franco, Fernando Henrique Cardoso e Luiz Inácio Lula da Silva) foram incapazes de fazer avançar o 'processo' da Reforma Sanitária brasileira. No limite, estes governantes produziram fatos que levaram à implantação tortuosa do SUS .(PAIM, 2009, p. 32).

Frente ao diagnóstico evidente de que a crise do Estado brasileiro se aprofunda, expresso pelo descompasso entre sua missão constitucional de prover direitos sociais universais e sua histórica subordinaçáo à classe dominante, os ditos 'novos modelos de gestão' não apenas nâo resolvem este dilema, como acentuam o caráter burguês do mesmo Estado.

$\mathrm{O}$ que se pretendeu aqui foi demonstrar a relação estreita que existe entre um processo político que abarca todas esferas do Estado brasileiro - o conjunto das reformas neoliberais e uma manifestação específica destas -, a proposta de Fundaçóes Estatais de Direito Privado, e, no caso, a FESF baiana. As diversas variáveis analisadas devem ser objeto de estudos mais detidos, em especial, avaliando e comparando o processo de implementação das diversas FEDP para uma compreensão mais minuciosa das políticas em curso.

No entanto, os fatos fundamentais que permitem classificar o modelo das FEDPs como partes das contrarreformas neoliberais são: a acomodação aos limites da LRF (e, portanto, do processo de ajuste fiscal); o não pagamento da contribuição patronal para o fundo de previdência pública, que agrava ainda mais a crise da previdência social; a precarização da força de trabalho, pois, ainda que na Bahia haja uma situação de maior precariedade do que o vínculo celetista, ao se olhar para a situação do serviço público antes de 1990, é impossível se discordar da perda de direitos que atravessou aquela categoria, que tem sido uma das pontas de lança da resistência ao processo de reformas neoliberais.

O problema da força de trabalho continua sendo central, e, segundo Rezende (2008), é agravado pelos 'novos modelos de gestáo':

[...] a forma de gestão da força de trabalho do setor (quase escravagista), não só não foi alterada, como foi amplamente precarizada e submetida a novos modos de degradação, tais como a ausência de concurso público, vínculos múltiplos e ilegais, ambientes de trabalho insalubres, construção de uma visão desqualificadora do trabalho no setor público, adoção de mecanismos nefastos de competitividade e valorização desigual dos trabalhadores em condiçóes de trabalho idênticas, dentre outras. (p. 34).

Por fim, ao se analisar a questão, deve-se evitar cair na falácia de que as FEDPs 'remam contra a maré do neoliberalismo' por representarem 'mais Estado' na área social. Esta falácia se baseia em uma leitura estrita de que a diferença fundamental entre o modelo, por exemplo, das OSs e o das FEDPs seria que uma é controlada diretamente pelo Estado e a outra não. Estudo de Ibañez \& Vecina Neto (2007) aponta para a identidade entre os projetos das OSs e das FEDPs: 
Na análise comparativa das caracteristicas da Fundação pública de direito privado proposta para gestão Hospitalar, não exclusivamente, com as outras a que mais apresenta pontos comuns são as organizaçôes sociais”.

No capitalismo neoliberal atual, as fronteiras entre a 'sociedade civil' e a 'sociedade política' estão ainda mais borradas do que à época em que Gramsci (2007) criou sua famosa expressão: "Estado = sociedade civil + sociedade política, isto é, hegemonia couraçada de coerção" (p. 244), o que significa dizer que os instrumentos de dominação de classe ancorados no Estado adquirem morfologias novas. Para escapar desta armadilha é preciso compreender o sentido da mudança da sociedade brasileira e do Estado brasileiro. Esta compreensão, dentro de uma análise crítica, observa que o capital ganha força, que a segregação social se aprofunda, que a dependência externa se acentua. Em uma sociedade assim, a modalidade de gestão ser mais ou menos 'Estado' tem uma importância colateral, sem as profundas transformaçóes ansiadas pelo movimento de reforma sanitária.

\section{Referências}

ASSEMBLEIA LEGISLATIVA DE SÃO PAULO. Comissão Parlamentar de Inquérito sobre a remuneração dos serviços médicos hospitalares. Sub-relatoria de Organizações Sociais. Sub-relatório. São Paulo: a Assembléia, 2008.

BIANCHI, A. O laboratório de Gramsci: filosofia, história e política. São Paulo: Alameda, 2008.

BORON, A. Estado, Capitalismo y Democracia en América Latina. Buenos Aires: Clacso, 2004.

CAMPOS, G. W. S. Reforma Política e Sanitária: A sustentabilidade do SUS em questão? Ciência e Saúde Coletiva, Rio de Janeiro, v. 12, n. 2, p. 301-306, abr. 2007.

CARNEIRO, F. F. et al. Dossiê ABRASCO: um alerta sobre os impactos dos agrotóxicos na saúde. Rio de Janeiro: ABRASCO, abr. 2012.

CENTRO BRASILEIRO DE ESTUDOS DE SAÚDE. A Questão Democrática na Área da Saúde; Assistência à saúde numa sociedade democrática. In: FLEURY, S.; BAHIA, L.; AMARANTE, P. (orgs.) Saúde em Debate: fundamentos da reforma sanitária. Rio de Janeiro: CEBES, 2008.

CHAVES, J. V.; RIBEIRO, J. A. C. Gasto Social Federal: uma análise da execução orçamentária de 2011. Brasília: IPEA, 2012.

FALEIROS, V. P. et al. A construção do SUS: histórias da reforma sanitária e do processo participativo. Brasília: Ministério da Saúde, 2006.

FATORELLI, M. L. Quem vai pagar a conta? Revista Poli: Saúde, educação e trabalho, Rio de Janeiro, a. 4, n. 26, jan./fev. 2013.

FATORELLI, M. L.; ÁVILA, R. Os números da dívida. Disponível em: <www.auditoriacidada.org.br>. Acesso em: 24 abr 2012.
FERNANDES, F. Poder e Contrapoder na América Latina. Rio de Janeiro: Jorge Zahar, 1981.

. Nova República? Rio de Janeiro: Jorge Zahar, 1985. . Em Busca do Socialismo. São Paulo: Xamã, 1995.

.O que é Revolução. In: PRADO JR., C.; FERNANDES, F. Clássicos sobre a revolução brasileira. São Paulo: Expressão Popular, 2000.

A Revolução Burguesa no Brasil: ensaio de interpretação sociológica. São Paulo: Globo, 2006.

FLEURY, S. (org.). Saúde e Democracia: a luta do CEBES. São Paulo: Lemos Editorial, 1997.

FUNDAÇÃO ESTATAL SAÚDE DA FAMÍLIA DA BAHIA. FESF-SUS Inovação Radical na Estratégia de Saúde da Família. Salvador: FESF/ SUS, 2009.

FURTADO, C. Pequena introdução ao desenvolvimento. São Paulo: Companhia Nacional, 1982.

GRAMSCI, A. Cadernos do Cárcere. 3. ed. Rio de Janeiro: Civilização Brasileira, 2007. v. 3.

GRANEMANN, S. Fundações Estatais: Projeto de Estado do Capital. In: BRAVO, M. I. S. et al (org.). Política de saúde na atual conjuntura: modelos de gestão e agenda para a saúde.2. ed. Rio de Janeiro: Rede Sirius/ADUFRJ-SSind, 2008.

IBAÑEZ, N.; VECINA NETO, G. Management models and Brazil's National Health System (SUS). Ciência e Saúde Coletiva, Rio de Janeiro, v. 12, suppl. 0, nov. 2007.

LOPEZ, A.; MOTA, C. G. História do Brasil: uma interpretação. São Paulo: Senac, 2008. 
MÉSZAROS, I. O desafio e o fardo do tempo histórico: o socialismo no século XXI. São Paulo: Boitempo, 2007.

OCKÉ-REIS, C. O.; SOPHIA, D. C. Uma crítica à privatização do sistema de saúde brasileiro: pela constituição de um modelo de proteção social público de atenção à saúde. Saúde em Debate, Rio de Janeiro, v. 33, n. 81, p.72-79, jan./abr. 2009.

PAN AMERICAN HEALTH ORGANIZATION/WORLD HEALTH ORGANIZATION. Health Situation in the Americas. Basic Indicators 2012. Washington: PAHOMHO, 2012. Disponivel em: <http://new.paho. org/hq/index.php?option=com_content\&task =view\&id=2470\&ltemid=2003> . Acesso em: 01 dez. 2012.

PAIM, J. S. Reforma Sanitária Brasileira: contribuição para a compreensão e crítica. Salvador: EDUFBA; Rio de Janeiro: FIOCRUZ, 2008.

Uma análise sobre o processo da Reforma Sanitária brasileira. Saúde em Debate, Rio de Janeiro, v. 33, n. 81, p. 27-37, jan./ abr. 2009.

PAIM, J. S.; TEIXEIRA, C. F. Configuração institucional e gestão do Sistema Único de Saúde: problemas e desafios. Ciência e Saúde Coletiva, Rio de Janeiro, v. 12, suppl. 0, nov. 2007.
PAN AMERICAN HEALTH ORGANIZATION; WORLD HEALTH ORGANIZATION. Health Situation in the Americas. Basic Indicators 2012. Washington: PAHO/WHO, 2012. Disponível em: <http:// new.paho.org/hq/index.php?option=com_content\&task =view\&id=2470\&ltemid=2003>. Acesso em: 01 dez. 2012.

REZENDE, C. A. P. O Modelo de Gestão do SUS e a ameaça neoliberal In: BRAVO, M. I. S. et al (orgs.). Política de saúde na atual conjuntura: modelos de gestão e agenda para a saúde. 2. ed. Rio de Janeiro: Rede Sirius/ADUFRJ-SSind, 2008.

SAMPAIO JÚNIOR, P. A. Entre a nação e a barbárie: os dilemas do capitalismo dependente em Caio Prado, Florestan Fernandes e Celso Furtado. Petrópolis, RJ: Vozes, 1999.

SANTOS, N. R. A Reforma Sanitária e o Sistema Único de Saúde: tendências e desafios após 20 anos. Saúde em Debate, Rio de Janeiro, v. 33, n. 81, p.13-26, jan./abr. 2009.

SOARES, L. T. R. Ajuste Neoliberal e Desajuste Social na América Latina. Rio de Janeiro: UFRJ, 1998.

Recebido para publicação em Abril/2012

Versão final em Maio/2013

Conflito de interesse: não houve

suporte financeiro: inexistente 